\title{
High flow nasal oxygen therapy in COVID-19 critically ill patients with acute hypoxemic respiratory failure: A prospective observational cohort study
}

\author{
Mohd Khan ${ }^{1}$, Jay Prakash ${ }^{1}$, Sudipto Banerjee ${ }^{1}$, Raman Kumar ${ }^{1}$, and Pradip Kumar \\ Bhattacharya $^{1}$ \\ ${ }^{1}$ Rajendra Institute of Medical Sciences
}

April 27, 2021

\begin{abstract}
Background: Acute hypoxemic respiratory failure (AHRF) is common in COVID-19. Tracheal intubation in such patients is fraught with higher mortality, therefore, high flow nasal oxygen therapy (HFNOT) is being used in AHRF. In this study, we aimed to determine the impact of HFNOT on oxygenation status and also various predictors of HFNOT failure. Methods: A prospective observational cohort study was conducted in COVID-positive critically ill adult patients (aged $>18$ years) with AHRF, who were unable to maintain $\mathrm{SpO} 2>90 \%$ on a non-rebreathing face mask at an oxygen flow [?]15 litres/minute. Respiratory variables $(\mathrm{PaO} 2 / \mathrm{FiO} 2, \mathrm{SpO} 2$, and $\mathrm{RR}$ ) before HFNOT (baseline), then at 1-hour, 6-hour, 7-day, and 14-day after HFNOT application, were recorded. Borg CR10 scale and visual analog scale were used to evaluate the subjective sensation of dyspnoea and comfort level respectively. Student's t, Mann-Whitney U or Wilcoxon signed-rank tests were used as applicable. Multivariate logistic regression and Receiver-Operating Characteristic (ROC) analyses were performed to determine factors associated with HFNOT failure. Results: 114 patients were included with HFNOT failure rate of $29 \%$. The Median $\mathrm{PaO} 2 / \mathrm{FiO} 2$ ratio at baseline (before initiation of HFNOT) was 99.5 (80-110) which significantly increased at various time points (1-hour, 6-hour, 7-days, and 14-day) after HFNOT initiation in the successful group. Patients reported significant improvement in sensation of breathlessness (9 [8-10], $3[2-4]$; $\mathrm{p}<0.001)$ as well as in comfort level $(2$ [1-2], 8 [4-9]; p $<0.001)$. Multivariate logistic regression analysis, SOFA $>7$, APACHE II $>20$, admission P/F ratio $<100$, D-dimer $>2 \mathrm{mg} / \mathrm{L}, \mathrm{IL}-6>40$ pg/mL, Random Blood Sugar $(\mathrm{RBS})>250 \mathrm{mg} / \mathrm{dL}, 6$-hour ROX Index $<3.5$, were independent prognostic factors of HFNOT failure. Conclusion: In COVID-19 patients with AHRF, the use of HFNOT significantly improved oxygenation levels at various time points after HFNOT initiation. Age, SOFA, APACHE II, and ROX scores, admission P/F ratio, IL-6, D-dimer, and RBS were independent prognostic factors of HFNOT failure in this cohort.
\end{abstract}

\section{High flow nasal oxygen therapy in COVID-19 critically ill patients with acute hypoxemic respiratory failure: A prospective observational cohort study}

Abstract:

Background: Acute hypoxemic respiratory failure (AHRF) is common in COVID-19. Tracheal intubation in such patients is fraught with higher mortality, therefore, high flow nasal oxygen therapy (HFNOT) is being used in AHRF. In this study, we aimed to determine the impact of HFNOT on oxygenation status and also various predictors of HFNOT failure.

Methods: A prospective observational cohort study was conducted in COVID-positive critically ill adult patients (aged $>18$ years) with $\mathrm{AHRF}$, who were unable to maintain $\mathrm{SpO} 2>90 \%$ on a non-rebreathing face mask at an oxygen flow [?]15 litres/minute. Respiratory variables $(\mathrm{PaO} 2 / \mathrm{FiO} 2, \mathrm{SpO} 2$, and $\mathrm{RR})$ before HFNOT (baseline), then at 1-hour, 6-hour, 7-day, and 14-day after HFNOT application, were recorded. Borg 
CR10 scale and visual analog scale were used to evaluate the subjective sensation of dyspnoea and comfort level respectively. Student's t, Mann-Whitney U or Wilcoxon signed-rank tests were used as applicable. Multivariate logistic regression and Receiver-Operating Characteristic (ROC) analyses were performed to determine factors associated with HFNOT failure.

Results: 114 patients were included with HFNOT failure rate of $29 \%$. The Median $\mathrm{PaO} 2 / \mathrm{FiO} 2$ ratio at baseline (before initiation of HFNOT) was 99.5 (80-110) which significantly increased at various time points (1-hour, 6-hour, 7-days, and 14-day) after HFNOT initiation in the successful group. Patients reported significant improvement in sensation of breathlessness (9 [8-10], 3 [2-4]; $\mathrm{p}<0.001)$ as well as in comfort level $(2$ [1-2], 8 [4-9]; $\mathrm{p}<0.001)$. Multivariate logistic regression analysis, SOFA $>7$, APACHE II $>20$, admission $\mathrm{P} / \mathrm{F}$ ratio $<100$, D-dimer $>2 \mathrm{mg} / \mathrm{L}, \mathrm{IL}-6>40 \mathrm{pg} / \mathrm{mL}$, Random Blood Sugar $(\mathrm{RBS})>250 \mathrm{mg} / \mathrm{dL}, 6$-hour ROX Index $<3.5$, were independent prognostic factors of HFNOT failure.

Conclusion: In COVID-19 patients with AHRF, the use of HFNOT significantly improved oxygenation levels at various time points after HFNOT initiation. Age, SOFA, APACHE II, and ROX scores, admission P/F ratio, IL-6, D-dimer, and RBS were independent prognostic factors of HFNOT failure in this cohort.

\section{Keywords:}

High Flow Nasal Oxygen, COVID-19, Critically-ill, Acute hypoxemic respiratory failure

\section{What's already known about this topic?}

High Flow Nasal Oxygen Therapy (HFNOT) is effective in improving oxygenation in acute hypoxemic respiratory failure in COVID-19 patients.

ROX index is a reliable predictor of HFNOT failure and the requirement of higher respiratory support.

\section{What does this article add?}

HFNOT improves comfort and relieves dyspnoea in patients presenting with acute hypoxemic respiratory failure.

Apart from the ROX index, D-dimer, IL-6, APACHE-II, SOFA scores, baseline PaO2/FiO2 ratio, and admission hyperglycemia are predictors of HFNOT failure.

\section{Article text}

High flow nasal oxygen therapy in COVID-19 critically ill patients with acute hypoxemic respiratory failure: A prospective observational cohort study

\section{Introduction :}

In December 2019, a deadly disease caused by the novel coronavirus (SARS CoV-2) emerged in Wuhan, China, which was termed as "coronavirus disease 2019 (COVID-19)" by World health Organization in the International Classification of Diseases (ICD). ${ }^{1}$ Virus enters into the lung through the inhalation route and infects lung parenchyma to cause severe COVID-19 pneumonia in $14 \%$ cases. $^{2}$ About $15.6-31 \%$ of COVID-19 patients develop acute respiratory distress syndrome (ARDS), ${ }^{3}$ which is clinically, characterized by acute onset of dyspnoea, hypoxemia, and appearance of bilateral diffuse radiological infiltrates. ${ }^{4}$ COVID-19 is a systemic illness caused by widespread endothelial injury. ${ }^{5}$ Hypoxemia in COVID-19 ARDS occurs due to presence of intrapulmonary ventilation-perfusion mismatch or shunt. Such patients most benefit from oxygen delivery devices which may be invasive or non-invasive. Invasive oxygen device (i.e., mechanical ventilator) requires tracheal intubation, which eventually carries considerable risk of complications (intensive care acquired weakness, ventilator associated pneumonia, ventilator dependence, ICU delirium etc) and mortality $(61 \%-96 \%){ }^{6,7}$

Use of non-invasive oxygen delivery devices, which include non-invasive ventilation (NIV) and High Flow Nasal Oxygen Therapy (HFNOT), has become routine. Nevertheless, during the initial phase of this pandemic, there were apprehensions regarding use of NIV and HFNOT due to perceived risk of aerosolization 
and exposures to clinical staff. ${ }^{8}$ But, subsequent investigation showed only limited exposure risks with the use of such devices, and, therefore, NIV and HFNOT both are being used in COVID-19 ARDS. ${ }^{9}$ NIV has various drawbacks such as patient intolerance due to discomfort and claustrophobia, mask leak and patient ventilator asynchrony, patient self-induced lung injury (P-SILI), inability to maintaining oral hygiene. HFNOT, on the other hand, has been shown to reduce the progression to Invasive mechanical ventilation (IMV), compared with other types of non-invasive oxygen therapy. ${ }^{10,11}$ In a recent prospective multicentre cohort study on 122 matched patients, in comparison with early intubation, HFNOT increased ventilator-free days by eight days. ${ }^{12}$ Therefore, HFNOT may be considered as initial respiratory support of choice in COVID-19 ARDS. Limited number of studies exploring the impact of HFNOT in COVID-19 pneumonia has been performed, albeit with small sample sizes. ${ }^{13-15}$ Therefore, we planned this study with aim to determine the impact of HFNOT on the oxygenation level in COVID-19 critically ill patients presenting with acute hypoxemic respiratory failure (AHRF). Primary objective was to record the change in $\mathrm{PaO}_{2} / \mathrm{FiO}_{2}$ ratio from baseline to various time points (1-hr, 6-hr, 7-day and 14 day) after initiation of HFNOT. Secondary objective was to evaluate the predictive factors of HFNOT failure (i.e., requirement of IMV or NIV).

Materials and methods Study design and setting

A prospective observational cohort study was conducted after approval from the institutional ethics committee and written informed consents from enrolled patients admitted at a designated COVID intensive care unit (ICU) of a government tertiary teaching hospital in East India. This study was performed in accordance with Guidelines set by the Strengthening the Reporting of Observational Studies in Epidemiology (STROBE).

\section{Study population}

Patients admitted between 2nd November, 2020 to 2nd February, 2021, were included who satisfied following inclusion criteria; 1 . critically ill adult (aged[?]18 years) patients, 2. COVID-positive status (SARS CoV2 detected in nasopharyngeal swab by real-time reverse transcription polymerase chain reaction assay), 3. presence of AHRF (defined as $\mathrm{PaO}_{2} / \mathrm{FiO}_{2}$ ratio $<300$ or peripheral oxygen saturation $<90 \%$ with respiratory rate $>25$ breaths per minute), 4. inability to maintain peripheral oxygen saturation [?] $90 \%$ on standard oxygen therapy (non-rebreathing face mask) at oxygen flow rate [?]15 litres/minute. Exclusion criteria were; age $<18$ years, tracheal intubation or NIV use prior to HFNOT, hemodynamic shock (defined as $\mathrm{SBP}<90$ $\mathrm{mmHg}$ or $\mathrm{MAP}<65 \mathrm{mmHg}$ or requirement of vasopressor).

\section{HFNOT protocol}

High flow nasal cannula was fitted into patients' nostrils and connected to a heated inspiratory circuit. Patients were instructed to keep their mouth closed and to wear surgical facemask over HFNOT cannula throughout ICU stay to maximize the oxygenation. On HFNOT device (AIRVO-2, Fisher \& Paykel Healthcare Corporation Limited, Auckland, New Zealand), initial flow rates and $\mathrm{FiO}_{2}$ were set at $50-60 \mathrm{~L} / \mathrm{min}$ and 80-100\% respectively. $\mathrm{FiO} 2$ was later down-titrated to attain the target $\mathrm{SpO}_{2}$ of just above $90 \%$. Inspiratory flow rates were adjusted to match the patient's inspiratory demand as manifested by clinical findings of respiratory failure (respiratory rate $>25 /$ minute, use of accessory muscles of respiration and perspiration). During HFNOT, patients were also instructed to lie down in prone-position for 2-hours/session with 3-4 such sessions per day. They were also instructed to perform incentive spirometry and steam inhalation every 3-4 hourly. Patients were encouraged to eat hospital kitchen food and protein-rich nutritional supplements. Supplemental parenteral nutrition, in the form of intravenous amino acid and omega-3 fatty acid, was also prescribed by treating physician if deemed necessary.

Initially HFNOT was used continuously; however, as patient's respiratory distress disappeared HFNOT was gradually weaned off using a protocol (increasing the time of venturi mask trials while stepwise decreasing $\mathrm{FiO}_{2}$ levels and flows). Many patients who required $\mathrm{FiO} 2[?] 60 \%$ and inspiratory flow of [?] 40 litres/minute with stable hemodynamics were shifted to a 20-bedded dedicated 'high flow ward' . However, in case of respiratory worsening or non-responders, higher respiratory support (NIV or IMV) was used to improve respiratory parameters. HFNOT failure was defined by the need of NIV or IMV as rescue therapy. 


\section{Data collection and study variables}

On a predesigned and printed case record form ( $\mathrm{CRF}$ ), demographic characteristics, disease severity (APACHE II) and organ dysfunction (SOFA) scores, vital signs, laboratory and the arterial blood gas parameters were sequentially entered by two authors (JP, SB) and reviewed and analysed by two independent authors (MSK, PKB). We collected respiratory variables such as $\left(\mathrm{PaO}_{2} / \mathrm{FiO}_{2}, \mathrm{SpO}_{2}\right.$, and RR) before HFNOT (baseline) and later at 1-hour, 6-hour, 7-day and 14-day after HFNOT application. The ROX index (ratio of $\mathrm{SpO}_{2} / \mathrm{FiO}_{2}$ to RR) was calculated at 2- hour and 6-hour of HFNOT. The subjective sensation of dyspnoea was evaluated using the Borg CR10 scale (from 0 - no dyspnoea - to 10 - maximum dyspnoea) and the comfort level was assessed by means of a visual analogue scale (from 1 - very uncomfortable to 10 - very comfortable); both scores were recorded before (baseline) and 1-hour after HFNOT initiation. All patients were followed up till day-28 or death, whichever was earlier.

\section{Statistical analysis}

Continuous data were expressed as mean \pm standard deviation or median with interquartile ranges (25th and 75th percentiles), depending upon skewness of distribution of data. Shapiro-Wilk test was performed to determine the normality of the data distribution. Dichotomous data were reported as number (percentage) and analysed using Fisher's exact test. The intergroup differences were analysed using Student's t test or Mann-Whitney U test. The intragroup differences between variables at different time points were compared using Friedman test and the Wilcoxon signed-rank test. Univariate analysis was performed to select statistically significant variables associated with HFNOT failure; these variables were entered in a stepwise logistic regression analysis to determine factors associated with HFNOT failure. Receiver-Operating Characteristic (ROC) analysis was performed and the areas under the ROC curve (AUROC) were calculated to identify the best predictor of HFNOT failure. All statistical tests were two-tailed, and P values [?]0.05 were considered statistically significant. All statistical analyses were run on Statistical Package for Social Sciences (SPSS) software (version 20.0, IBM, Armonk, NY, USA).

\section{Results}

A total of 271 patients were screened during study period, out of which 262 patients had AHRF and HFNOT was used as first line therapy in 128 patients. Finally, 114 patients were included into study, out of which, 33 patients $(29 \%)$ failed to tolerate HFNOT, resulting in escalation to either NIV ( 25 patients) or IMV ( 8 patients) (Figure 1).

Demographic characteristics of all included patients $(n=114)$ are tabulated in table 1. Mean age of the patients was 60.3+-14.4 years which was significantly higher in HFNOT failure than that of HFNOT success group ( $\mathrm{p}<0.001$ ). Male patients accounted for the majority $(81 \%)$ of HFNOT cohort. Key comorbidities were diabetes mellitus (50\%) hypertension $(26 \%)$ and CKD $(8 \%)$. Majority of patients required therapeutic anticoagulation $(81 \%)$, whereas the rest were on prophylactic anticoagulants. Almost all patients required IV Dexamethasone $6 \mathrm{mg} /$ day. About $90 \%$ patients received intravenous Remdesivir. Twenty-three patients $(20 \%)$ had high procalcitonin value $(2 \mathrm{ng} / \mathrm{mL})$ and hence required escalation of antibacterial therapy. Median $\mathrm{PaO}_{2} / \mathrm{FiO}_{2}$ ratio at baseline (before initiation of HFNOT) was 99.5 (80-110) which gradually and significantly increased at various time points (1-hour, 6-hour, 7-days and 14-day) after HFNOT initiation in successful group (Figure 2, Table 2). This improvement was found to be significantly higher in HFNOT success group compared to failure group (Figure 2, Table 2).

Patients reported significant improvement in sensation of breathlessness as well as in comfort level after application of HFNOT. This improvement was more in the HFNOT success group compared to the failure group (Figure 3, Table 3).

It was observed that compared to successful group, the HFNOT failure group was significantly older (70.7+10.7, 56+-13.6, p<0.001), with lower baseline median SpO2 (66 [60-73], 80 [67.5-87]; $\mathrm{p}<0.001$ ), lower baseline median $\mathrm{P} / \mathrm{F}$ ratio (87 [65.5-100], 100 [89.5-110]; $\mathrm{p}<0.001$ ), lower mean ROX index at 1-hour (2.8+-0.4, $3.4+-0.4 ; \mathrm{p}<<0.001)$ and 6-hour $(3.0+-0.5,4.4+-0.9 ; \mathrm{p}<<0.001)$, higher median heart rates $(119+-15.7$, 
111+-12.7; $\mathrm{p}<0.001)$, higher APACHE II ( 21.6+-2.1, 12.4+-1.8; $\mathrm{p}<0.001)$ and SOFA $(9.2+-0.9,5.5+-.9$; $\mathrm{p}<0.001$ ) and higher values of IL-6, D dimer and random blood sugar levels (Table 1). On univariate analysis, age $>65$ years, APACHE II $>20$ and SOFA $>7$, 2-hour ROX, 6-hour ROX index, Baseline $\mathrm{P} / \mathrm{F}$ ratio, $\mathrm{SpO} 2<70 \%$, D-dimer $>2 \mathrm{mg} / \mathrm{L}$, IL- $6>40 \mathrm{pg} / \mathrm{mL}$ and $\mathrm{RBS}>250 \mathrm{mg} / \mathrm{dL}$, absence of prone positioning were statistically significant factors (Odds ratio $>1, \mathrm{p}<0.05$ ) contributing to the HFNOT failure (Table 4 ). After incorporating all these factors related to HFNOT failure into multivariate logistic regression analysis, we found that age $>65$ years, SOFA $>7$, APACHE II $>20$, admission $\mathrm{P} / \mathrm{F}$ ratio $<100, \mathrm{SpO} 2<70 \%, \mathrm{HR}>120 \mathrm{bpm}$, D-dimer $>2 \mathrm{mg} / \mathrm{L}, \mathrm{IL}-6>40 \mathrm{pg} / \mathrm{mL}, \mathrm{RBS}>250 \mathrm{mg} / \mathrm{dL}, 6$-hour ROX Index $<3.5,1$-hour ROX Index $<3$, were independent prognostic factors of HFNOT failure. Further, on ROC analysis, we found, highest AUROCs with, APACHE II, SOFA score, D dimer, ROX index at 6-hour,1 hour, IL-6 and RBS. Among these indicators, the APACHE-II greater than 20 was the most relevant predictor of HFNOT failure (Table 4, Figure 4).

Complications specific to HFNOT application were noted in $50.9 \%$ patients, in which, epistaxis (18.4\%) and air hunger $(15.7 \%)$ were the most common complications Table 5). However, one patient developed spontaneous tension pneumothorax which required immediate intercostal drain tube placement following which, patient dramatically improved and survived to hospital discharge.

\section{Discussion}

This study, which was conducted to evaluate the impact of HFNOT in COVID-19 critically ill patients who developed severe AHRF, showed the gradual and significant impact of HFNOT on oxygenation status ( $\mathrm{PaO} 2 / \mathrm{FiO} 2)$ over four consecutive time points (i.e.; at 1-hour, 6-hour, 7-day and 14-day). The majority of our cohort had profound hypoxemia (median [IQR] $\mathrm{PaO}_{2} / \mathrm{FiO} 2$ ratio, 99.5 [80-110] $\mathrm{mmHg}$ ) at admission to ICU. Even with such a low P/F ratio, HFNOT remarkably outperformed with a success rate of $71 \%$. However, the effect was assessed to be significantly higher in the group of the patients who were successfully managed on HFNOT compared to those who failed HFNOT. Significant improvement in $\mathrm{PaO} 2 / \mathrm{FiO} 2$ ratio may be explained by adequate and reliable oxygen delivery (both concentration flow) meeting the patients' demand, regularly wearing surgical mask over high flow cannula, self-awake proning, incentive spirometry and steam inhalation in our cohort. Application of surgical mask over high flow cannula significantly improves $\mathrm{PaO} 2 / \mathrm{FiO} 2$ from $83(+-22)$ to $111\left(+-38(\mathrm{p}<0.001) .{ }^{16}\right.$

Profound hypoxemia before HFNOT application recorded in our study is comparable to that reported in two studies conducted in COVID-19 patients. ${ }^{13,17}$ In a prospective study conducted in 293 enrolled patients at two tertiary hospitals in Cape Town, South Africa, the median (IQR) PaO2/FiO2 ratio was 68 (54-92) with more than half of the patients failed to continue on HFNOT. ${ }^{18}$ Similarly, in a retrospective study conducted on 105 patients, median (IQR) $\mathrm{PaO} 2 / \mathrm{FiO} 2$ ratio was 116.0 (102.1-132.0) with lower HFNOT failure rate $38 \% .{ }^{13}$ Our HFNOT failure rate is comparable to previously reported HFNOT failure rates (32-53\%). ${ }^{18,19}$ Significant predictors of HFNOT failure in our study, which were obtained using multivariate and ROC analysis, were older age ( $>65$ years), higher APACHE II and SOFA scores, lower P/F ratio $(<100)$, higher IL-6 (>40 pg/mL), D dimer (>2 mg/L) values and hyperglycaemia (RBS $>250 \mathrm{mg} / \mathrm{dL})$. We observed ROX score at 6 hours was a better predictor compared to ROX score at 2 hours. Similarly, two recent investigations noted lower ROX score at 6 hours was highly predictive of HFNOT failure. ${ }^{13,18}$

In our study, about $36 \%$ of patients followed proning, the frequency of which was greater in the HFNOT success group. Failure to prone was found to be a significant predictor of HFNOT failure on univariate analysis (OR 3.42, CI 1.28-9.19; $\mathrm{p}<0.05$ ). In a series of 20 patients with ARDS treated with HFNC or NIV, improved oxygenation with awake proning was recorded. ${ }^{20}$ Similarly, in a pilot study on 50 consecutive COVID-19 patients presenting to ED with $\mathrm{SpO} 2<93 \%$ on supplemental oxygen, five minutes of awake proning improved $\mathrm{SpO}_{2}$ from $84 \%$ to $94 \% .^{21}$

HFNOT significantly reduced subjective sensation to dyspnea and improved comfort score in our cohort. Similarly, other studies also reported better dyspnoea score and comfort levels with HFNOT when compared to standard oxygen therapy. ${ }^{22,23}$ Improved comfort level with HFNOT could be possibly due to improved humidification of the respiratory gas. ${ }^{23}$ 
The main strengths of study were its prospective nature and comparatively large sample size., Another strength, compared to other studies was that we captured oxygenation data at $7^{\text {th }}$ day and $14^{\text {th }}$ day also, in order to assess long term effect of HFNOT on oxygenation. Additionally, we have analysed various predictive variables of HFNOT failure using two different statistical tests; multivariate logistic regression and ROC analysis. Main limitation is that being a single centre study, the results need to be critically interpreted before extrapolating to patients in different geographical locations, with diverse comorbidities and severity scores. Another limitation was that we could not study any radiological variable and also failed to capture data on hospital acquired infections. Compared to NIV, during HFNOT, better provision of enteral protein-energy delivery was possible due to less incidence of abdominal distension and improved tolerance to HFNOT. This aspect should be tested and explored further in a future research. Another factor which needs attention is active mobilization, incentive spirometry practice with HFNOT may have reduced the incidence of critical-illness myopathy or polyneuropathy despite various risk factors present (such as prolonged ICULOS, steroid use, and hyperglycaemia). This aspect should also be a leading point of exploration in future directions.

Compared to all previous studies, we recorded higher severity of illness (admission mean APACHE II, 15.1+4.6 and SOFA, 6.5+-1.9). in other studies APACHE II and SOFA scores were in the range between 8-10 and 3-5 respectively. ${ }^{11,13,18}$ The probably reasons of higher severity scores could be delayed presentation to our facility and many of them already had spent an average of 6-7 days in other COVID facilities before referral to our centre. This also explains lower levels of baseline hypoxemia and higher respiratory rate at admission to our facility. The successful group spent longer time in ICU due to profound hypoxemia at baseline and difficult weaning off HFNOT due to probably pulmonary fibrosis or peripheral pulmonary artery embolisms patients may have developed over the course of disease.

Debate continues on the best modality of respiratory support in severe COVID-19 pneumonia and AHRF. In this regard, HFNOT offers various significant advantages over invasive and other non-invasive devices in terms of higher oxygenation score, decreased risk of tracheal intubation (compared to SOT) ${ }^{24,25}$ better comfort score and less incidence of nasal and facial skin breakdown, better oral hygiene, speech, higher compliance to device continuation, lesser need of sedative, higher response to awake self-proning (compared to NIV), ${ }^{22}$ better comfort level, lower dyspnoea score (compared to SOT and NIV), lesser incidence of hemodynamic collapse, shock, complications such as barotrauma, critical illness polyneuropathy, death (compared to IMV).

Nevertheless, NIV may be better than HFNOT in improving oxygenation parameters due to higher mean airway pressure, however, at the cost of various complication and intolerance. Moreover, less sick patients (APACHE II $<10$ ) with stable hemodynamics requiring HFNOT, can be managed in 'high flow ward' with basic monitoring and nursing requirements. That may spare a greater number of ICU beds for sicker COVID 19 patients. In our case, the majority of patients on HFNOT were shifted to a "high flow ward", after stabilization of respiratory parameters after a week's time, where they were gradually weaned off HFNOT to SOT and then room air.

\section{Conclusion}

In COVID-19 patients with AHRF, use of HFNOT significantly improved oxygenation level, dyspnoea score and comfort level. Age $>65$ years, SOFA $>7$, APACHE II $>20$, admission $\mathrm{PaO} 2 / \mathrm{FiO} 2$ ratio[?]100, SpO2[?]70\%, $\mathrm{HR}>120 \mathrm{bpm}$, D-dimer $>2 \mathrm{mg} / \mathrm{L}$, IL-6 $>40 \mathrm{pg} / \mathrm{mL}$, RBS $>250 \mathrm{mg} / \mathrm{dL}, 6$-hour ROX score[?]3.5, and 1-hour ROX score[?]3, were independent prognostic factors of HFNOT failure. We strongly recommend selecting HFNOT as an initial respiratory support device to manage acute hypoxemic respiratory failure in COVID19, due to its effectiveness, safety and ease of application with minimal training and minimal monitoring and nursing requirement.

\section{References}

1. Guan WJ, Ni ZY, Hu Y, Liang WH, Ou CQ, He JX, Liu L, Shan H, Lei CL, Hui DS, Du B. Clinical characteristics of coronavirus disease 2019 in China. New England journal of medicine. 2020 Apr 30;382(18):1708-20. 
2. Wu Z, McGoogan JM. Characteristics of and important lessons from the coronavirus disease 2019 (COVID-19) outbreak in China: summary of a report of 72314 cases from the Chinese Center for Disease Control and Prevention. Jama. 2020 Apr 7;323(13):1239-42.

3. Wang D, Hu B, Hu C, Zhu F, Liu X, Zhang J, Wang B, Xiang H, Cheng Z, Xiong Y, Zhao Y. Clinical characteristics of 138 hospitalized patients with 2019 novel coronavirus-infected pneumonia in Wuhan, China. Jama. 2020 Mar 17;323(11):1061-9.

4. Li X, Ma X. Acute respiratory failure in COVID-19: is it "typical" ARDS?. Critical Care. 2020 Dec;24:1-5.

5. Teuwen LA, Geldhof V, Pasut A, Carmeliet P. COVID-19: the vasculature unleashed. Nature Reviews Immunology. 2020 Jul;20(7):389-91.

6. Richardson S, Hirsch JS, Narasimhan M, Crawford JM, McGinn T, Davidson KW, Barnaby DP, Becker LB, Chelico JD, Cohen SL, Cookingham J. Presenting characteristics, comorbidities, and outcomes among 5700 patients hospitalized with COVID-19 in the New York City area. Jama. 2020 May 26;323(20):2052-9.

7. Grasselli G, Zangrillo A, Zanella A, Antonelli M, Cabrini L, Castelli A, Cereda D, Coluccello A, Foti G, Fumagalli R, Iotti G. Baseline characteristics and outcomes of 1591 patients infected with SARS-CoV-2 admitted to ICUs of the Lombardy Region, Italy. Jama. 2020 Apr 8;323(16):1574-81.

8. Namendys-Silva SA. Respiratory support for patients with COVID-19 infection. The lancet Respiratory medicine. 2020 Apr 1;8(4):e18.

9. Haymet A, Bassi GL, Fraser JF. Airborne spread of SARS-CoV-2 while using high-flow nasal cannula oxygen therapy: myth or reality?. Intensive care medicine. 2020 Dec;46(12):2248-51.

10. Frat JP, Thille AW, Mercat A, Girault C, Ragot S, Perbet S, Prat G, Boulain T, Morawiec E, Cottereau A, Devaquet J. High-flow oxygen through nasal cannula in acute hypoxemic respiratory failure. New England Journal of Medicine. 2015 Jun 4;372(23):2185-96.

11. Ou X, Hua Y, Liu J, Gong C, Zhao W. Effect of high-flow nasal cannula oxygen therapy in adults with acute hypoxemic respiratory failure: a meta-analysis of randomized controlled trials. CmAj. 2017 Feb 21;189(7):E260-7.

12. Mellado-Artigas R, Ferreyro BL, Angriman F, Hernandez-Sanz M, Arruti E, Torres A, Villar J, Brochard L, Ferrando C. High-flow nasal oxygen in patients with COVID-19-associated acute respiratory failure. Critical Care. 2021 Dec;25(1):1-0.

13. Hu M, Zhou Q, Zheng R, Li X, Ling J, Chen Y, Jia J, Xie C. Application of high-flow nasal cannula in hypoxemic patients with COVID-19: a retrospective cohort study. BMC pulmonary medicine. 2020 Dec;20(1):1-7.

14. Xia J, Zhang Y, Ni L, Chen L, Zhou C, Gao C, Wu X, Duan J, Xie J, Guo Q, Zhao J. High-Flow Nasal Oxygen in Coronavirus Disease 2019 Patients With Acute Hypoxemic Respiratory Failure: A Multicenter, Retrospective Cohort Study. Critical care medicine. 2020 Nov;48(11):e1079.

15. Vianello A, Arcaro G, Molena B, Turato C, Sukthi A, Guarnieri G, Lugato F, Senna G, Navalesi P. Highflow nasal cannula oxygen therapy to treat patients with hypoxemic acute respiratory failure consequent to SARS-CoV-2 infection. Thorax. 2020 Nov 1;75(11):998-1000.

16. Montiel V, Robert A, Robert A, Nabaoui A, Marie T, Mestre NM, Guillaume M, Laterre PF, Wittebole X. Surgical mask on top of high-flow nasal cannula improves oxygenation in critically ill COVID-19 patients with hypoxemic respiratory failure. Annals of intensive care. 2020 Dec;10(1):1-7.

17. Patel M, Gangemi A, Marron R, Chowdhury J, Yousef I, Zheng M, Mills N, Tragesser L, Giurintano J, Gupta R, Gordon M. Retrospective analysis of high flow nasal therapy in COVID-19-related moderateto-severe hypoxaemic respiratory failure. BMJ open respiratory research. 2020 Aug 1;7(1):e000650.

18. Calligaro GL, Lalla U, Audley G, Gina P, Miller MG, Mendelson M, Dlamini S, Wasserman S, Meintjes G, Peter J, Levin D. The utility of high-flow nasal oxygen for severe COVID-19 pneumonia in a resource-constrained setting: A multi-centre prospective observational study. EClinicalMedicine. 2020 Nov 1;28:100570.

19. Mejia VA, Isaza DA, Turizo MF, Trespalacios EV, Rincon JA. High flow nasal cannula useful for severe SARSs-CoV-2 pneumonia. Medicina Intensiva. 2021 Feb 10. 
20. Ding L, Wang L, Ma W, He H. Efficacy and safety of early prone positioning combined with HFNC or NIV in moderate to severe ARDS: a multi-center prospective cohort study. Critical care. 2020 Dec $1 ; 24(1): 28$.

21. Caputo ND, Strayer RJ, Levitan R. Early self-proning in awake, non-intubated patients in the emergency department: a single ED's experience during the COVID-19 pandemic. Academic Emergency Medicine. 2020 May;27(5):375-8.

22. Spoletini G, Mega C, Pisani L, Alotaibi M, Khoja A, Price LL, Blasi F, Nava S, Hill NS. High-flow nasal therapy vs standard oxygen during breaks off noninvasive ventilation for acute respiratory failure: a pilot randomized controlled trial. Journal of critical care. 2018 Dec 1;48:418-25.

23. Schwabbauer N, Berg B, Blumenstock G, Haap M, Hetzel J, Riessen R. Nasal high-flow oxygen therapy in patients with hypoxic respiratory failure: effect on functional and subjective respiratory parameters compared to conventional oxygen therapy and non-invasive ventilation (NIV). BMC anesthesiology. 2014 Dec;14(1):1-7.

24. Rochwerg B, Granton D, Wang DX, Helviz Y, Einav S, Frat JP, Mekontso-Dessap A, Schreiber A, Azoulay E, Mercat A, Demoule A. High flow nasal cannula compared with conventional oxygen therapy for acute hypoxemic respiratory failure: a systematic review and meta-analysis. Intensive care medicine. 2019 May;45(5):563-72.

25. Zhu Y, Yin H, Zhang R, Ye X, Wei J. High-flow nasal cannula oxygen therapy versus conventional oxygen therapy in patients after planned extubation: a systematic review and meta-analysis. Critical Care. 2019 Dec;23(1):1-2.

Tables:

Table 1. Comparisons of demographic, clinical and laboratory parameters between HFNOT success and failure groups

\begin{tabular}{|c|c|c|c|c|}
\hline Parameters & All $(n=114)$ & $\begin{array}{l}\text { HFNOT } \\
\text { success group } \\
(n=81)\end{array}$ & $\begin{array}{l}\text { HFNOT failure } \\
\text { group }(\mathrm{n}=33)\end{array}$ & $P$ value \\
\hline $\begin{array}{l}\text { Age (years), } \\
\text { mean } \pm \mathrm{SD}\end{array}$ & $60.3 \pm 14.4$ & $56 \pm 13.6$ & $70.7 \pm 10.7$ & $<0.001$ \\
\hline Male, $n$ (\%) & $92(80.7)$ & $64(79.0)$ & $28(84.8)$ & 0.472 \\
\hline Comorbidities & Comorbidities & Comorbidities & Comorbidities & Comorbidities \\
\hline $\begin{array}{l}\text { Hypertension, } \\
n(\%)\end{array}$ & $30(26.3)$ & $21(25.9)$ & $9(27.3)$ & 0.881 \\
\hline $\begin{array}{l}\text { Diabetes } \\
\text { Mellitus, n (\%) }\end{array}$ & $57(50)$ & $41(50.6)$ & $16(48.5)$ & 0.834 \\
\hline $\begin{array}{l}\text { Chronic kidney } \\
\text { disease, n (\%) }\end{array}$ & $9(7.9)$ & $5(6.2)$ & $4(12.1)$ & 0.285 \\
\hline $\begin{array}{l}\text { APACHE-II } \\
\text { Score, mean } \pm \\
\text { SD }\end{array}$ & $15.1 \pm 4.6$ & $12.4 \pm 1.8$ & $21.6 \pm 2.1$ & $<0.001$ \\
\hline $\begin{array}{l}\text { SOFA score, } \\
\text { mean } \pm \mathrm{SD}\end{array}$ & $6.5 \pm 1.9$ & $5.5 \pm 0.9$ & $9.2 \pm 0.9$ & $<0.001$ \\
\hline $\begin{array}{l}\text { Duration of } \\
\text { symptoms } \\
\text { before HFNOT } \\
\text { (days), mean } \pm \\
\text { SD }\end{array}$ & $5.9 \pm 2.1$ & $4.9 \pm 1.4$ & $8.3 \pm 1.5$ & $<0.001$ \\
\hline $\begin{array}{l}\text { Duration of } \\
\text { HFNOT }(d), \\
\text { mean } \pm \text { SD }\end{array}$ & $9.1 \pm 3.7$ & $10.7 \pm 2.3$ & $5.2 \pm 3.7$ & $<0.001$ \\
\hline
\end{tabular}




\begin{tabular}{|c|c|c|c|c|}
\hline $\begin{array}{l}\operatorname{ICU} \operatorname{LOS}(d), \\
\text { mean } \pm \mathrm{SD}\end{array}$ & $15.4 \pm 4.8$ & $16.7 \pm 3.2$ & $12.0 \pm 6.3$ & $<0.001$ \\
\hline $\begin{array}{l}\text { Prone } \\
\text { positioning }\end{array}$ & $41(35.9)$ & $35(43.2)$ & $6(18.2)$ & 0.0114 \\
\hline $\begin{array}{l}\text { Use of steroids, } \\
\text { n (\%) }\end{array}$ & $110(96.5)$ & 77 (95.1) & $33(100)$ & 0.1936 \\
\hline $\begin{array}{l}\text { Vitals before } \\
\text { HFNOT: }\end{array}$ & & & & \\
\hline $\begin{array}{l}\text { HR } \\
(\text { beats } / \min ) \text {, } \\
\text { mean } \pm \mathrm{SD}\end{array}$ & $113.5 \pm 14$ & $111 \pm 12.7$ & $119 \pm 15.7$ & 0.006 \\
\hline $\begin{array}{l}\text { MAP }(\mathrm{mmHg}) \\
\text { mean } \pm \mathrm{SD}\end{array}$ & $69(65-78)$ & $69(65-78)$ & $67(60-78)$ & 0.700 \\
\hline $\begin{array}{l}\text { RR } \\
\text { (breaths/min), } \\
\text { median (IQR) }\end{array}$ & $34(31-35)$ & $33(31-35)$ & $34(32-39)$ & 0.203 \\
\hline $\begin{array}{l}\mathrm{PaCO}_{2}, \\
\text { median (IQR) }\end{array}$ & $40(32-45)$ & $40(34-45)$ & $40(31-45)$ & 0.411 \\
\hline $\begin{array}{l}\text { SpO2 (\%), } \\
\text { median (IQR) }\end{array}$ & $78(65-84)$ & $80(65-87)$ & $66(60-73)$ & $<0.001$ \\
\hline $\begin{array}{l}\mathrm{PaO} 2 / \mathrm{FiO} 2 \\
\text { ratio, mean } \pm \\
\mathrm{SD}\end{array}$ & $97 \pm 29.2$ & $103.4 \pm 29.3$ & $81.4 \pm 22.5$ & 0.001 \\
\hline$n(\%$ & $73(64.0)$ & $46(56.8)$ & $27(81.8)$ & 0.0114 \\
\hline $\begin{array}{l}\text { ROX index (at } \\
\text { 1-hour), mean } \pm \\
\text { SD }\end{array}$ & $3.2 \pm 0.5$ & $3.4 \pm 0.4$ & $2.8 \pm 0.4$ & $<0.001$ \\
\hline $\begin{array}{l}\text { ROX index (at } 6 \\
\text { hour), mean } \pm \\
\text { SD }\end{array}$ & $4.0 \pm 1.1$ & $4.4 \pm 0.9$ & $3.0 \pm 0.5$ & $<0.001$ \\
\hline $\begin{array}{l}\text { D-dimer } \\
(\mathrm{mg} / \mathrm{L}), \text { mean } \\
\pm \mathrm{SD}\end{array}$ & $1.7 \pm 1.00$ & $1.2 \pm 0.6$ & $3.0 \pm 0.7$ & $<0.001$ \\
\hline $\begin{array}{l}\text { IL-6 }(\mathrm{pg} / \mathrm{mL}), \\
\text { median (IQR) }\end{array}$ & $26(17-48)$ & $23(14-29)$ & $67(47-91)$ & $<0.001$ \\
\hline $\begin{array}{l}\mathrm{RBS}(\mathrm{mg} / \mathrm{dL}), \\
\text { mean } \pm \mathrm{SD}\end{array}$ & $222.1 \pm 107.5$ & $176.4 \pm 71.5$ & $334.2 \pm 99.0$ & $<0.001$ \\
\hline $\begin{array}{l}\text { ICU mortality, } \\
\text { n (\%) }\end{array}$ & $20(17.5)$ & $0(0)$ & $20(60.6)$ & $<0.001$ \\
\hline $\begin{array}{l}\text { 28-day } \\
\text { mortality, n } \\
\text { (\%) }\end{array}$ & $31(27.2)$ & $0(0)$ & $31(93.9)$ & $<0.001$ \\
\hline
\end{tabular}

HFNOT high-flow nasal oxygen therapy, IL-6 Interleukin-6, APACHE-II Acute Physiology and Chronic Health Evaluation II, SOFA Sepsis-related Organ failure Assessment, ROX index Respiratory rateoxygenation index, RBS random blood sugar, $\mathrm{PaO} 2$ Partial pressure of oxygen in arterial blood, FiO2 fraction of inspired oxygen concentration, $\mathrm{PaCO}_{2}$ Partial pressure of carbon dioxide in arterial blood, $\mathrm{HR}$ heart rate,MAP mean arterial pressure, $\mathrm{RR}$ respiratory rate.

Table 2. Change in respiratory parameters from baseline (after initiation of HFNOT) to various time points (1-hr, 6-hr, 7-day and 14-day) after initiation of HFNOT in success and 
failure groups

\begin{tabular}{lllll}
\hline \multirow{2}{*}{ PaO2/FiO2 ratio } & Time points & All patients $(\mathbf{N}=\mathbf{1 1 4})$ & HFNOT Success $(\mathbf{n = 8 1})$ & HFNOT Failure $(\mathbf{n}=\mathbf{3 3})$ \\
& Baseline & $99.5(80-110)$ & $100(89.5-110)$ & $87(65.5-100)$ \\
& 1-hour & $114(100-130)$ & $120(100-140)$ & $100(84.5-120)$ \\
& 6-hour & $126(97.75-143.25)$ & $130(120-153.5)$ & $81(69-96.5)$ \\
7-day & $170(129-200)$ & $192(150-201)$ & $67(66-79)$ \\
P value++ & 14-day & $250(199.50-281.75)$ & $250(221-290)$ & $80(70-105)$ \\
Respiratory rate & Baseline & $<0.001$ & $<0.001$ & $<0.001$ \\
& 1-hour & $34(31-35)$ & $33(31-35)$ & $34(32-37)$ \\
& 6-hour & $29.5(28-32)$ & $30(26.5-30)$ & $33(32-35)$ \\
& 7-day & $24(22-28)$ & $29(28-30)$ & $30(28.5-33)$ \\
$\mathbf{P}$ value ++ & 14-day & $24(22-26)$ & $24(22-26)$ & $28(22-32.25)$ \\
SpO & & $<0.001$ & $22(18-23)$ & $<0.001$ \\
& Baseline & $78(65.75-84)$ & $<0.001$ & $66(60-73)$ \\
& 1-hour & $94(91-98)$ & $80(67.5-87)$ & $91(90-92)$ \\
& 6-hour & $94(91-97)$ & $96(92-99)$ & $90(89-95.5)$ \\
$\mathbf{P}$ value ++ & 7-day & $97(92-98)$ & $95(92-97.5)$ & $89.5(85-90)$ \\
\hline
\end{tabular}

+ Mann Whitney U test, ++Friedman test; all values are expressed as median $(25 \%$ to $75 \%$ inter quartile range)

Table 3. Dyspnea Borg scale and comfort VAS among between HFNOT Success and Failure groups

\begin{tabular}{llll}
\hline & All patients & HFNOT Success $(\mathbf{n}=\mathbf{8 1})$ & HFNOT Failure $(\mathbf{n}=$ \\
Dyspnea Borg scale (baseline) & $9(8-10)$ & $9(8-9)$ & $10(9-10)$ \\
Dyspnea Borg scale (After 1-hour HFNOT) & $3(2-4)$ & $3(2-3)$ & $4(4-5)$ \\
P value++ & $<0.001$ & $<0.001$ & $<0.001$ \\
Comfort VAS (baseline) & $2(1-2)$ & $2(1-3)$ & $2(1-2)$ \\
Comfort VAS (After 1-hour HFNOT) & $8(4-9)$ & $9(8-9)$ & $3(2-4)$ \\
P value++ & $<0.001$ & $<0.001$ & $<0.001$ \\
\hline
\end{tabular}

+Mann Whitney U test between HFNOT failure and success groups, ++ Wilcoxon Signed Ranks test between variables at two time points in same group, all values are expressed as median $(25 \%$ to $75 \%$ inter quartile range)

Table 4. Predictors of HFNOT failure using multivariate logistic regression analysis and ROC analysis

\begin{tabular}{|c|c|c|c|c|c|c|}
\hline Variables & $\begin{array}{l}\text { Univariate } \\
\text { analysis } \\
\text { (OR with } \\
95 \% \mathrm{CI} \text { ) }\end{array}$ & $\mathbf{P}$ & $\begin{array}{l}\text { Multivariate } \\
\text { analysis } \\
\text { (OR) }\end{array}$ & $\mathbf{P}$ & $\begin{array}{l}\text { AUROC } \\
(95 \% \text { CI })\end{array}$ & $\mathbf{P}$ \\
\hline Age $>65$ years & $\begin{array}{l}8.70(3.46 \text { to } \\
21.89)\end{array}$ & $<0.001$ & 8.43 & $<0.001$ & $\begin{array}{l}0.801(0.717- \\
0.885)\end{array}$ & $<0.001$ \\
\hline $\begin{array}{l}\text { APACHE-II } \\
\text { score }>20\end{array}$ & $\begin{array}{l}40.00(10.38 \\
\text { to } 154.00)\end{array}$ & $<0.001$ & 16.20 & $<0.001$ & $\begin{array}{l}0.985(0.967- \\
1.000)\end{array}$ & $<0.001$ \\
\hline
\end{tabular}




\begin{tabular}{|c|c|c|c|c|c|c|}
\hline $\mathrm{SOFA}>7$ & $\begin{array}{l}260.00 \\
(49.70 \text { to } \\
1360.33)\end{array}$ & $<0.001$ & 78.00 & $<0.001$ & $\begin{array}{l}0.935(0.864- \\
1.000)\end{array}$ & $<0.001$ \\
\hline $\mathrm{P} / \mathrm{F}$ ratio $<100$ & $\begin{array}{l}3.42(1.28 \text { to } \\
9.20)\end{array}$ & 0.0146 & 5.83 & $<0.001$ & $\begin{array}{l}0.723(0.623 \\
-0.823)\end{array}$ & $<0.001$ \\
\hline $\begin{array}{l}\text { 1-hour ROX } \\
\text { Index }<3\end{array}$ & $\begin{array}{l}68.40(19.30 \\
\text { to } 242.46)\end{array}$ & $<0.001$ & 15.20 & $<0.001$ & $\begin{array}{l}0.922(0.860- \\
0.984)\end{array}$ & $<0.001$ \\
\hline $\begin{array}{l}\text { Admission } \\
\mathrm{SpO} 2<70 \%\end{array}$ & $\begin{array}{l}5.92(2.36 \text { to } \\
14.82)\end{array}$ & $<0.001$ & & $<0.001$ & $\begin{array}{l}0.726(0.624- \\
0.828)\end{array}$ & $<0.001$ \\
\hline $\begin{array}{l}\text { 6-hour ROX } \\
\text { Index }<3.5\end{array}$ & $\begin{array}{l}260.00 \\
(49.69 \text { to } \\
1360.33)\end{array}$ & $<0.001$ & 25.67 & $<0.001$ & $\begin{array}{l}0.978(0.949- \\
1.000)\end{array}$ & $<0.001$ \\
\hline $\begin{array}{l}\text { Admission } \\
\text { D- } \\
\text { dimer }>2 \mathrm{mg} / \mathrm{L}\end{array}$ & $\begin{array}{l}63.64(16.56 \\
\text { to } 244.58)\end{array}$ & $<0.001$ & 23.33 & $<0.001$ & $\begin{array}{l}0.970(0.944- \\
0.996)\end{array}$ & $<0.001$ \\
\hline $\begin{array}{l}\text { Admission } \\
\mathrm{RBS}>250 \\
\mathrm{mg} / \mathrm{dL}\end{array}$ & $\begin{array}{l}15.75(5.63 \\
\text { to } 44.03)\end{array}$ & $<0.001$ & 10.50 & $<0.001$ & $\begin{array}{l}0.893(0.826- \\
0.961)\end{array}$ & $<0.001$ \\
\hline $\begin{array}{l}\text { Admission } \\
\text { IL-6 }>40 \\
\mathrm{pg} / \mathrm{mL}\end{array}$ & $\begin{array}{l}52.31(13.88 \\
\text { to } 197.16)\end{array}$ & $<0.001$ & 34.00 & $<0.001$ & $\begin{array}{l}0.940(0.889- \\
0.991)\end{array}$ & $<0.001$ \\
\hline $\begin{array}{l}\text { Admission } \\
\mathrm{HR}>120 \\
\mathrm{bpm}\end{array}$ & $\begin{array}{l}4.56 \\
(1.63-12.75)\end{array}$ & 0.004 & 3.47 & $<0.001$ & $\begin{array}{l}0.613(0.490- \\
0.736)\end{array}$ & $<0.001$ \\
\hline $\begin{array}{l}\text { Prone } \\
\text { positioning- } \\
\text { No }\end{array}$ & $\begin{array}{l}3.42 \\
(1.28-9.19)\end{array}$ & 0.0146 & & & & \\
\hline Gender-male & $\begin{array}{l}1.49 \\
(0.49-4.43)\end{array}$ & 0.6043 & & & & \\
\hline $\begin{array}{l}\text { Comorbidity- } \\
\text { present }\end{array}$ & $\begin{array}{l}2.65 \\
(0.92-7.64)\end{array}$ & 0.0718 & & & & \\
\hline
\end{tabular}

HFNOT high-fow nasal oxygen therapy, IL-6 Interleukin-6, APACHE-II Acute Physiology and Chronic Health Evaluation II, SOFA Sepsis-related Organ failure Assessment, ROX index Respiratory rateoxygenation index, RBS random blood sugar, $\mathrm{P} / \mathrm{F} \mathrm{PaO2} / \mathrm{FiO} 2$, AUROC area under receiver operating characteristic curve, OR odds ratio, CI confidence interval

Table 5. Various complication of HFNOT:

\begin{tabular}{llll}
\hline Complications & All patients (N=114) & HFNOT Success $(\mathbf{n}=\mathbf{8 1})$ & HFNOT Failure (n=33) \\
Air Hunger, n (\%) & $18(15.8)$ & $5(6.1)$ & $13(39.4)$ \\
Epistaxis, n (\%) & $21(18.4)$ & $14(17.3)$ & $7(21.2)$ \\
Pressure ulcer at nares, n (\%) & $10(8.8)$ & $10(12.3)$ & $0(0)$ \\
Abdominal Distension & $4(3.5)$ & $4(49.4)$ & $0(0)$ \\
Nasal dryness & $4(3.5)$ & $3(3.7)$ & $0(0)$ \\
Pneumothorax & $1(0.9)$ & $1(1.2)$ & $10(30.3)$ \\
None & $55(48.2)$ & $45(55.6)$ & \\
\hline
\end{tabular}

+Fisher's exact test 
Figure legends:

Figure 1. Flow chart of subject screening and eligibility and allocation to various oxygen support devices

Figure 2. Box plots of median (IQR) $\mathrm{PaO} 2 / \mathrm{FiO} 2$ ratios at various time points in HFNOT success and failure groups

Figure 3. Box plots of dyspnoea Borg scale and, comfort VAS of HFNOT success and failure groups

Figure 4. ROC curves of a). Age, APACHE II, SOFA, RBS, IL-6, D-dimer, HR, b). ROX index-1hr, ROX index-6hr, $\mathrm{PaO} 2 / \mathrm{FiO} 2$ ratio (before HFNOT), SpO2 (before HFNOT) for HFNOT failure

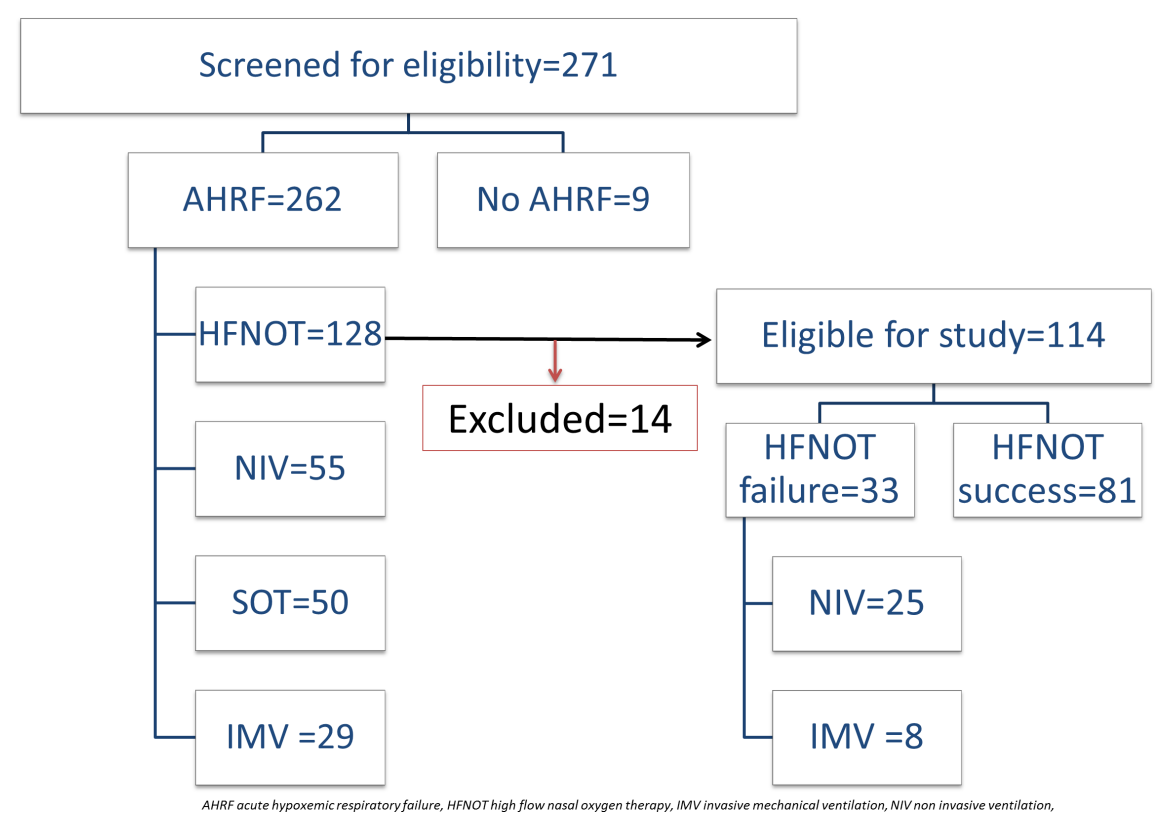



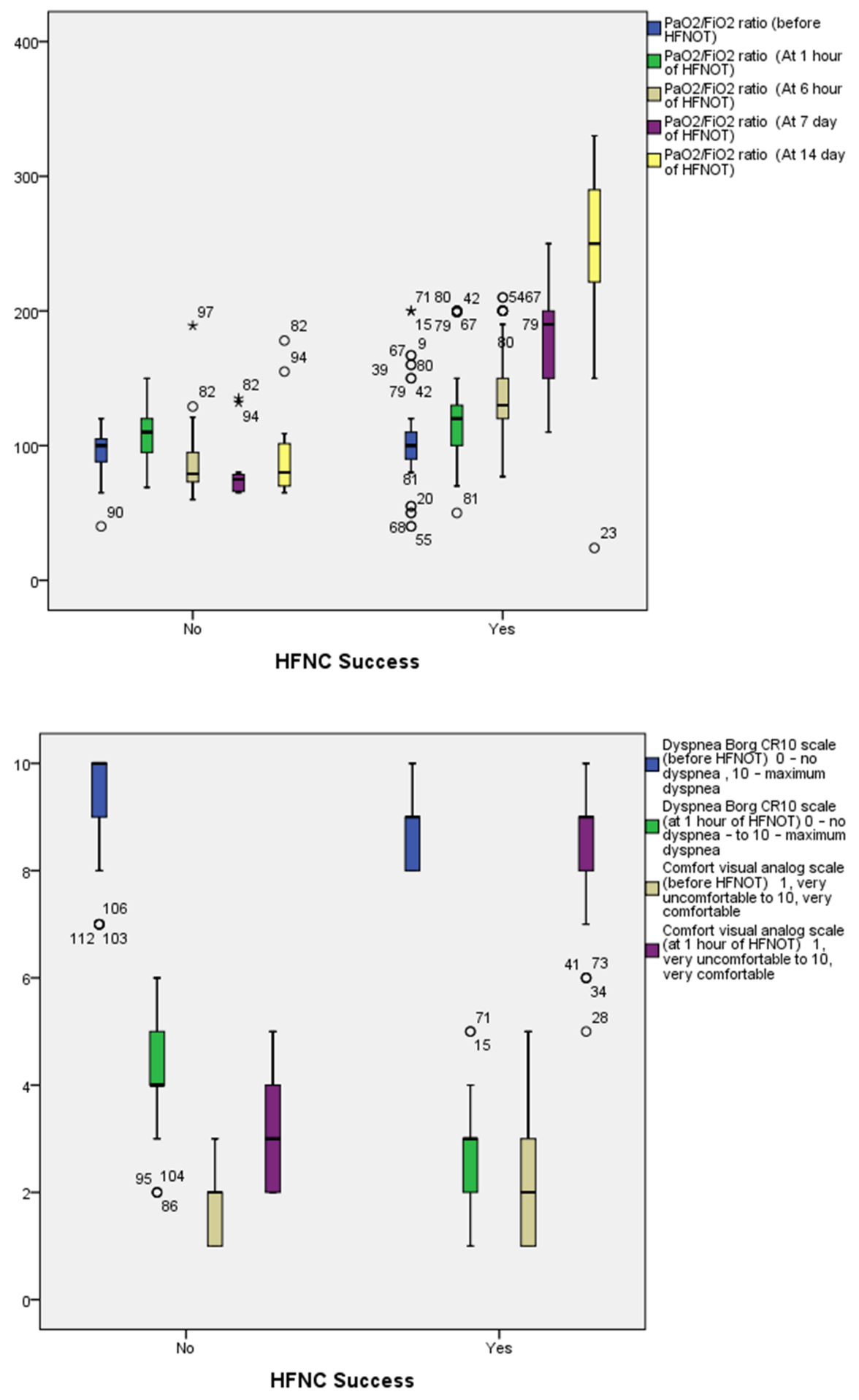
a.

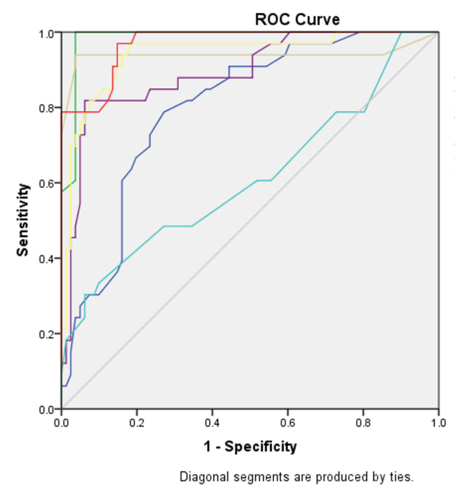

b.

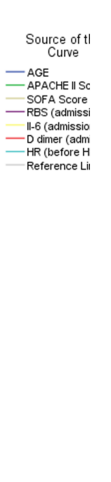

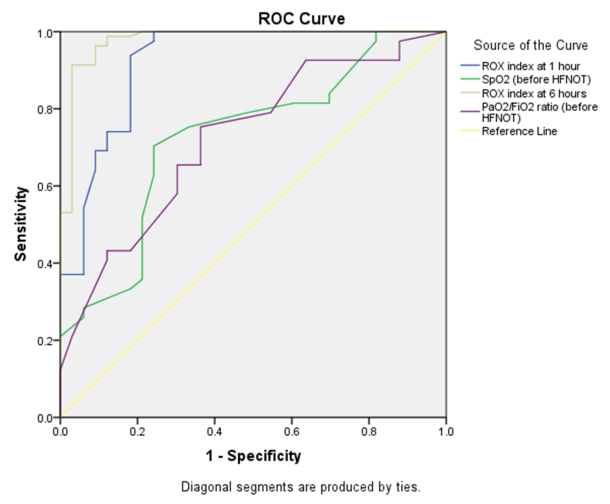

